\title{
A STUDY OF THE PULMONARY BLOOD VOLUME IN MAN BY QUANTITATIVE RADIOCARDIOGRAPHY *
}

\author{
By C. GIUNTINI, $\dagger$ M. L. LEWIS, $\ddagger$ A. SALES LUIS,§ ANd R. M. HARVEI \\ (From the Department of Medicine, Columbia University, College of Physicians \& Surgeons, \\ and the Cardiopulmonary Laboratory of the First Medical Division and the Chest \\ Service, Columbia University Division, Bellevue Hospital, New York, N. Y.)
}

(Submitted for publication February 6, 1963; accepted June 20, 1963)

Determination of the pulmonary blood volume, as distinguished from the central blood volume, has been hampered by the inaccessibility of the outflow of the pulmonary circulation to sampling. Recently, this difficulty has been circumvented by combined catheterization of the right and left hearts, which allows calculation of pulmonary mean transit time from arterial dilution curves obtained by injection of label into the pulmonary artery and left atrium (1-4). The information thus obtained provides the best available estimate of pulmonary blood volume but is restricted to a relatively small group of patients.

A different approach is provided by external counting techniques. Double-peaked curves, named radiocardiograms (5), are obtained by injecting a gamma-emitting label into either a peripheral vein, the right atrium, or the right ventricle, and monitoring its dilution in the cardiac cavities with a scintillation detector collimated over the precordium. It is possible, in most instances, to separate completely the right and left components of radiocardiograms; thus two dilution curves, respectively upstream and downstream to the pulmonary circulation, can be obtained (Figure 1). However, these precordial curves cannot be considered as ordinary dye-dilution curves, since their characteristics depend on the contributions of several circulatory sections. This is particularly true for the left component of radiocardiograms, which, with the type of collimator commonly used, is due, before the time of intracardiac recirculation,

* This investigation was supported by U. S. Public Health Service research grants HE-02001-08 and HE05741 from the National Heart Institute, Bethesda, Md.

$\dagger$ Research Fellow (grant HTS-5443), National Heart Institute. Present address: Centro di Medicina Nucleare, University of Pisa, Pisa, Italy.

$\ddagger$ Postdoctoral Research Fellow (grant HF-11,921-C1), U. S. Public Health Service.

$\S$ Gulbenkian Fellow. to label circulating in the left heart chambers and in vessels downstream from the aortic valves, such as the coronary vessels, the thoracic aorta, etc. Conceivably, the use of a narrow or focusing collimator might facilitate the analysis of the left curve, making this curve similar to a common dye concentration curve. The counting rate obtained with these collimators, however, is greatly influenced by small variations in the geometric relationship between detector and source. Furthermore, the low efficiency of such detectors sharply reduces the counting rate, thereby affecting the statistical accuracy of the recorded curves. Thus, it appears desirable to use a fairly wide collimator and to devise a method for measuring the pulmonary transit time that takes into consideration the composite nature of the left precordial curve.

Several investigators have postulated that an estimate of the pulmonary mean transit time may be derived from precordial curves (6-10). All the proposed methods, however, lead to a gross overestimation of the pulmonary mean transit time, since they include in it transit times through other circulatory sections. In previous work from this laboratory, an attempt was made to define the mean pulmonary circulation time by taking the mid-point of the interval between the appearance of the label in the left side of the heart and the peak counting rate of the left curve (11). This empirical procedure yields values considerably smaller than those given by the preceding methods, but the estimate of the mean pulmonary circulation time may carry an uncertainty up to one-half of the intervals between the onset and the peak of the left curve.

The purpose of this paper is to describe a new method that will reduce the uncertainty by which the mean pulmonary transit time can be estimated from radiocardiograms. The validity and the lim- 


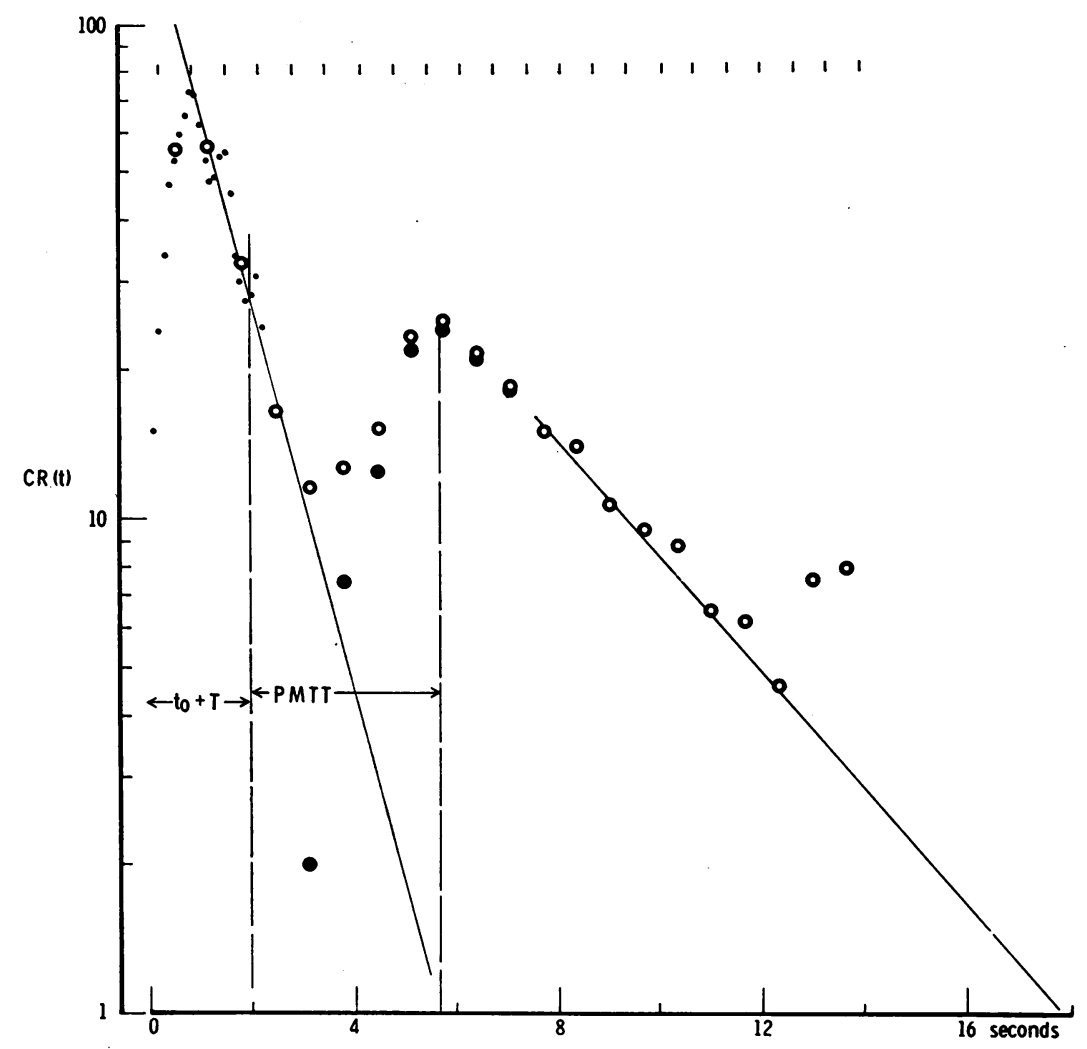

Fig. 1. A SEMILOGarith MiC PLOT OF A RADIOCARDIOGRAM OBTAINED AT REST IN A patient without heart disease. $\mathrm{Cr}(\mathrm{t})=$ counting rate; $\mathrm{t}_{0}=$ time of first ejection after injection; $\mathrm{T}=$ turnover time of right ventricle; $\mathrm{PMTT}=$ pulmonary mean transit time. Open circles represent the counting rate averaged over each heart cycle; solid circles represent the left curve after subtraction of the extrapolated right ventricular counting rate ; small dots represent the counting rate at every 0.1 second; vertical marks at the top indicate the QRS complex.

its of this method will be evaluated on the basis of a theoretical reconstruction of the precordial curves. Values of pulmonary blood volume under several physiologic and pathologic conditions will be presented.

\section{METHODS}

\section{Basic principle of the method}

Assuming that each side of the heart behaves hemodynamically as a single mixing chamber, and neglecting for the moment the pulmonary circulation, we may represent the central circulation by two compartments of equal size perfused in series by the same flow (Figure 2, left). If flow is considered to be continuous, the concentration in the left heart, $L H$, of an indicator injected instantaneously in the right heart, $R H$, is described by the equation

$$
C_{L H}(t)=C_{R H}(0)(\dot{Q} t / V) e^{-\dot{Q} t / V},
$$

where $\dot{Q}$ is the flow, $V$ the volume of each chamber, and $C_{R H}(0)$ the concentration in $R H$ at the moment of injection.
According to Equation 1, $C_{L H}(t)$ reaches its peak when $t=T=V / \dot{Q}$, where $T$ is the turnover time of each compartment.

In fact, the presence of the pulmonary circulation between $R H$ and $L H$ causes a delay and a change in contour of the concentration curve of the indicator in $L H$ (Figure 2 , right). It may be postulated that the displacement of the peak of $C_{L H}$ with respect to $T$ is closely related to the pulmonary mean transit time, $P M T T$. The latter may be approximated by means of the expression

$$
P M T T \simeq t_{p}-T,
$$

where $t_{p}$ is the time at which $C_{L H}$ reaches the peak, and $T$ is, by definition, the time when $C_{R H}$ is $37 \%$ of $C_{R H}(0)$. The pulmonary blood volume, $\mathrm{PBV}$, is then obtained, in the usual way, as the product of the cardiac output and pulmonary mean transit time, $P M T T$.

\section{Extension of the principle to radiocardiography}

The application of Equation 2 to precordial curves involves four major assumptions that need some consideration. 
The first assumption is that the right heart behaves hemodynamically as a single mixing chamber. When the injection of label is made into the right atrium close to the tricuspid valve or directly into the right ventricle, the mean transit time of the right heart may be equated to that of the right ventricle. If one assumes adequate mixing of tracer with circulating blood in the right ventricle, it is possible to derive, in a simple way, from the right curve of the radiocardiogram, the mean transit time of blood in the right ventricle.

The second assumption is that the left curve of the radiocardiogram is also due to a single mixing chamber. As already noted, however, it is practically impossible, by precordial counting, to isolate a single chamber of the left heart. In fact, even if vascular sections outside the heart cavities cannot appreciably influence the counting rate at the time of the peak of the left curve, the peak itself is always determined by the activity in the left atrium and left ventricle. It is, therefore, necessary to investigate the effect on $t_{p}$ of the composite nature of the left peak.

The third assumption, difficult to verify, is that the mixing volumes of the right and left heart are equal. Hence, variations in $t_{p}$ due to differences of these mixing volumes must be assessed.
Finally, the fourth assumption implicit in Equation 2, that the dispersion of the pulmonary transit times about the mean does not significantly displace the peak of the left curve, needs evaluation.

\section{Evaluation of the method}

An estimate of the complex effects of the factors above on the time of occurrence of the peak of the left curve has been obtained from a theoretical model of the central circulation.

Expected behavior of a label in the central circulation as derived from a mathematical model. The central circulation consists of the four heart chambers and the pulmonary vascular bed, perfused in series by the same flow. If the pulmonary circulation is treated as a labyrinth of pathways characterized by different transit times, and if it is assumed that mixing is complete in each cardiac chamber, and that the atria effect dispersion of the indicator in a manner analogous to that of the ventricles, the central circulation (Figure 3 ) is amenable to simple mathematical analysis. The concentration of an indicator, $C_{2}(t)$, at any point 2 downstream can be related to the concentration, $C_{1}(t-\theta)$, at any point 1 upstream at some earlier time
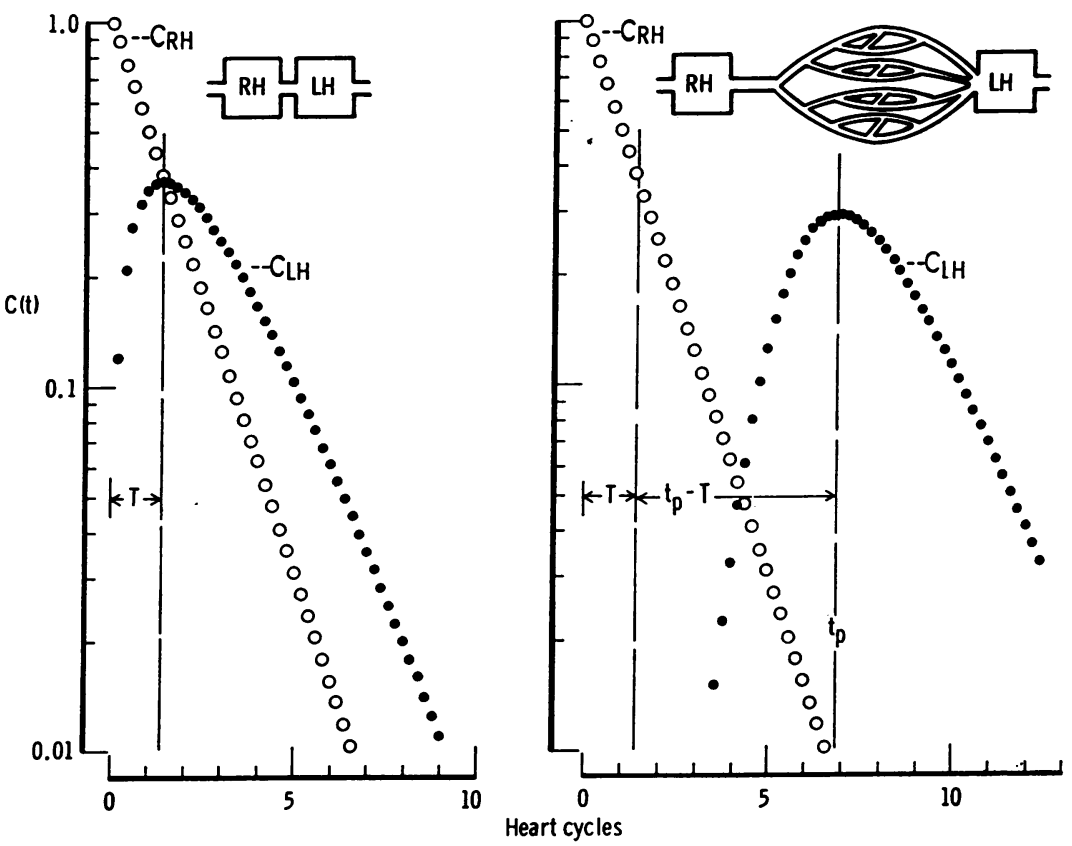

Fig. 2. Left: A SEMILOGARITHMIC GRAPH OF tIME CONCENTRATION CURVES OF AN INDICATOR INJECTED INTO THE PROXIMAL CHAMBER OF A TWO-CHAMBER SYSTEM, THE COMPONENTS OF WHICH ARE OF EQUAL SIZE AND PERFUSED BY THE SAME FLOW. $C_{R H}=$ concentration in the first chamber $(R H) ; C_{L H}=$ concentration in the second chamber $(\mathrm{LH}) ; \mathrm{T}=$ turnover time of each chamber.

Right: ILLUSTRATION OF THE DISPLACEMENT OF THE CONCENTRATION CURVE OF THE SECOND CHAMBER BY THE INTERPOSITION OF A LABYRINTH OF TRANSIT SECTIONS BETWEEN THE TWO CHAMBERS. The transit times through the labyrinth have been simulated with a normal distribution (mean, 5 heart cycles; SD, 1 heart cycle); $t_{p}-T$ is 5.4 heart cycles. 

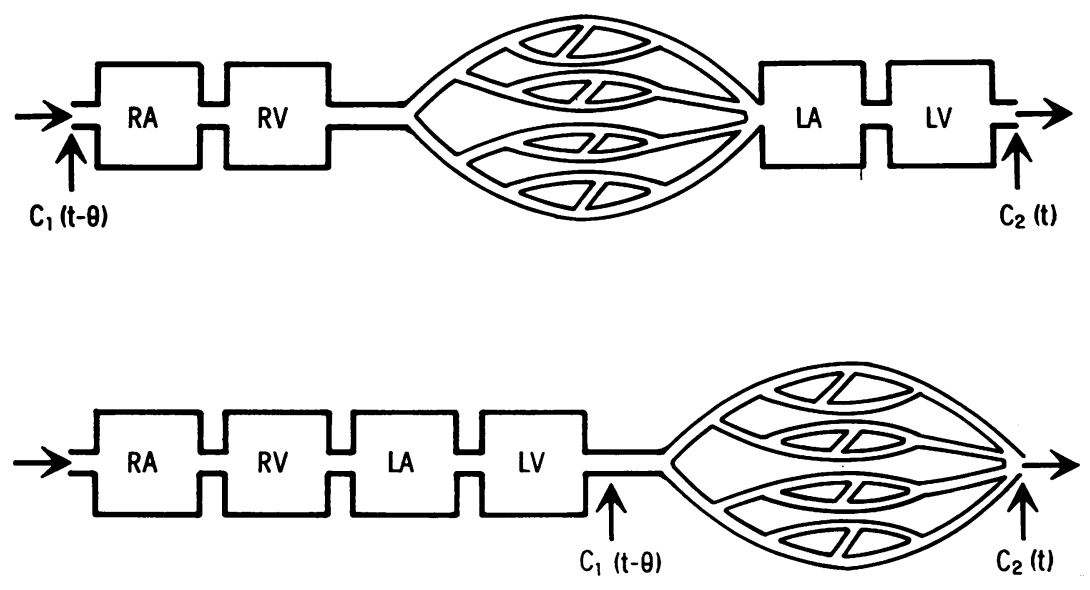

Fig. 3. Above: a schematic representation of the central circulation. $R A=$ right atrium, $R V=$ right ventricle, $L A=$ left atrium, and $L V=$ left ventricle. The pulmonary circulation is interposed between the RV and LA.

Below: THE NATURAL ORDER OF THE COMPONENTS OF THE CENTRAL Circulation HAS BEEN ALTERED TO FACILITATE THE MATHEMATICAL ANALYSIS OF THE CONCENTRATION OF AN INDICATOR IN A CHAMBER DOWNSTREAM TO THE PULMONARY CIRCULATION AFTER INJECTION IN A CHAMBER UPSTREAM TO IT. For discussion, see text.

by the equation

$$
C_{2}(t)=\int_{0}^{t} C_{1}(t-\theta) p(\theta) d \theta
$$

where $p(\theta)$ is the frequency function of the transit times between points 1 and 2 . Equation 3 represents the convolution or superposition integral of $C_{1}(t)$ and $p(t)$. Equations of this type are widely used to describe transport functions in dynamic systems (12-14).

Arranging the order of the structures as illustrated in the lower frame of Figure 3, and expressing $C_{1}(t)$ as a sum of exponential terms, Equation 3 becomes

$$
C_{z p}(t)=\int_{0}^{t} \sum_{j=1}^{z} a_{j} e^{-K_{j}(t-\theta)} p(\theta) d \theta .
$$

The constant, $K_{j}$, is defined by the equation,

$$
K_{j}=\log _{e}\left(1-\frac{S V}{V_{j}}\right),
$$

where $S V$ is the stroke volume and $V_{j}$ the maximal volume of the chamber. In the symmetrical solution for a series of chambers each with a different $K_{j}$, the constant $a_{j}$ takes the following form:

$$
\begin{aligned}
& a_{1}=\frac{K_{2} K_{3} \cdots K_{2} C(0)}{\left(K_{2}-K_{1}\right)\left(K_{3}-K_{1}\right) \cdots\left(K_{z}-K_{1}\right)}, \\
& a_{2}=\frac{K_{2} K_{3} \cdots K_{2} C(0)}{\left(K_{1}-K_{2}\right)\left(K_{3}-K_{2}\right) \cdots\left(K_{z}-K_{2}\right)}, \text { etc. }
\end{aligned}
$$

In Equations 6, $C(0)$ represents the concentration of indicator in the first chamber at the moment of injection.

Reconstruction of "left-heart" activity curves. The calculations on the model have been performed with the purpose of constructing time-activity curves that may be com- pared with left-heart curves obtained in man under various conditions. To this end, in addition to the hemodynamic parameters considered in the previous section, it is necessary to introduce the counting efficiencies of the leftheart chambers. The counting efficiency given in terms of "effective volume," $W_{j}$, is

$$
W_{j}=k \bar{\eta}_{j} V_{j}
$$

where $k$ is a constant depending on the characteristics of the isotope and of the detecting equipment, $\bar{\eta}_{j}$ is the average fraction of radiations emitted from any point within each chamber that reach the crystal, and $V_{j}$ is the volume of each chamber (11).

An estimate of $W_{j}$ has been derived experimentally from a distribution of efficiency for a point source of $I^{131}$ in a water bath, on which has been superimposed an outline of the heart drawn from anatomic data (15). With reference to the effective volume of the right ventricle, $W_{R V}$, taken as $100, W_{L A}$ and $W_{L V}$ are 43 and 38 , respectively, for a normal heart, with the equipment and collimation used. The effective volume has also been determined with a phantom of the heart immersed in a water-filled jar simulating the chest; values of 48 and 42 were found for $W_{L A}$ and $W_{L V}$, respectively. Therefore, these figures have been used for a normal-sized heart to transform concentrations within the chambers, expressed in counts per minute per milliliter, into the counting rate, in counts per minute of the recorded curve.

Values of $W_{j}$ for chambers of abnormal size have been estimated from the distribution of efficiency for a point source, assuming concentric enlargement of the chambers. Since these estimates represent only approximations of the efficiencies, values $\pm 10 \%$ of those estimated have been used to test the sensitivity of the reconstructed curves to 
TABLE I

Effect of varying parameters on calculation of pulmonary mean transit time in a model of the central circulation*

\begin{tabular}{|c|c|c|c|c|c|c|c|c|}
\hline SV & $\mathrm{V}_{\mathrm{RV}}$ & $\mathrm{V}_{\mathrm{LA}}$ & $\mathbf{V}_{\mathbf{L V}}$ & $\mathbf{W}_{\text {LA }}$ & $W_{L V}$ & Distribution & $t_{p}-\mathrm{T}_{\mathrm{RV}}$ & $\Delta$ \\
\hline$m l$ & $m l$ & $m l$ & $m l$ & $m l$ & $m l$ & & \multicolumn{2}{|c|}{ heart cycles } \\
\hline 85 & 123 & 45 & 126 & $27(30,24)$ & $38(34,42)$ & $\mathbf{a}$ & $5.5(5.4,5.5)$ & +0.5 \\
\hline 85 & 123 & 119 & 126 & $51(56,46)$ & $38(34,42)$ & $\mathrm{a}$ & $5.9(5.9,6.0)$ & +0.9 \\
\hline 85 & 123 & 119 & 126 & $51(56,46)$ & $38(34,42)$ & $\mathbf{b}$ & $5.7(5.6,5.8)$ & +0.7 \\
\hline 85 & 123 & 119 & 126 & $51(56,46)$ & $38(34,42)$ & c & $11.2(11.2,11.3)$ & +1.2 \\
\hline 65 & 182 & 34 & 97 & $27(30,24)$ & $32(29,35)$ & $\mathrm{a}$ & $4.5(4.4,4.6)$ & -0.5 \\
\hline 65 & 182 & 34 & 97 & $27(30,24)$ & $32(29,35)$ & $\vec{b}$ & $4.5(4.4,4.6)$ & -0.5 \\
\hline 65 & 182 & 34 & 97 & $27(30,24)$ & $32(29,35)$ & c & $10.0(9.9,10.0)$ & 0.0 \\
\hline 65 & 182 & 91 & 97 & $43(47,39)$ & $32(29,35)$ & c & $10.6(10.4,10.6)$ & +0.6 \\
\hline 65 & 182 & 175 & 97 & $57(63,51)$ & $32(29,35)$ & c & $11.2(11.1,11.3)$ & +1.2 \\
\hline 65 & 182 & 175 & 97 & $57(63,51)$ & $32(29,35)$ & $\mathrm{d}$ & $10.9(10.8,11.0)$ & -0.1 \\
\hline 65 & 91 & 182 & 175 & $57(63,51)$ & $46(41,51)$ & c & $12.1(12.0,12.2)$ & +2.1 \\
\hline 65 & 182 & 175 & 190 & $57(63,51)$ & $46(41,51)$ & a & $6.2(6.0,6.3)$ & +1.2 \\
\hline 65 & 182 & 175 & 190 & $57(63,51)$ & $46(41,51)$ & c & $11.6(11.4,11.7)$ & +1.6 \\
\hline 65 & 182 & 175 & 190 & $57(63,51)$ & $46(41,51)$ & d & $12.2(12.0,12.3)$ & +1.2 \\
\hline 65 & 308 & 91 & 94 & $43(39,47)$ & $32(35,29)$ & $\mathbf{c}$ & $9.2(9.1,9.3)$ & -0.8 \\
\hline 65 & 182 & 276 & 190 & $66(73,59)$ & $46(41,51)$ & c & $12.2(12.1,12.4)$ & +2.2 \\
\hline 65 & 291 & 276 & 190 & $66(73,59)$ & $46(41,51)$ & C & $11.5(11.4,11.7)$ & +1.5 \\
\hline 65 & 190 & 276 & 291 & $66(73,59)$ & $57(51,63)$ & $\mathbf{c}$ & $12.5(12.3,12.7)$ & +2.5 \\
\hline 45 & 386 & 126 & 131 & $48(53,43)$ & $38(34,42)$ & c & $8.1(7.9,8.2)$ & -1.9 \\
\hline 45 & 126 & 386 & 131 & $74(81,67)$ & $38(34,42)$ & $\mathbf{c}$ & $13.5(13.3,13.6)$ & +3.5 \\
\hline 45 & 202 & 386 & 131 & $74(81,67)$ & $38(34,42)$ & c & $13.1(13.0,13.3)$ & +3.1 \\
\hline 45 & 202 & 386 & 427 & $74(81,67)$ & $64(58,70)$ & c & $14.1(13.7,14.5)$ & +4.1 \\
\hline 45 & 427 & 386 & 214 & $74(81,67)$ & $46(41,51)$ & c & $11.8(11.6,12.1)$ & +1.8 \\
\hline 45 & 427 & 386 & 131 & $74(81,67)$ & $38(34,42)$ & c & $11.1(10.9,11.2)$ & +1.1 \\
\hline 45 & 427 & 386 & 131 & $74(81,67)$ & $38(34,42)$ & d & $13.5(13.2,13.7)$ & +2.5 \\
\hline 45 & 427 & 386 & 475 & $74(81,67)$ & $64(58,70)$ & c & $13.0(12.6,13.6)$ & +3.0 \\
\hline
\end{tabular}

* $\mathrm{SV}=$ stroke volume, $\mathrm{V}_{\mathrm{RV}}$ = right ventricular volume, $\mathrm{V}_{\mathrm{LA}}=$ left atrial volume, $\mathrm{V}_{\mathrm{LV}}=$ left ventricular volume, $\mathrm{W}_{\mathrm{LA}}=$ effective volume of the left atrium, and $\mathrm{W}_{\mathrm{LV}}=$ effective volume of the left ventricle.

Letters refer to type of distribution of pulmonary transit times imposed: a = normal distribution: mean, 5 heart cycles; $\mathrm{SD}, 1$ heart cycle. $\mathrm{b}=$ frequency function of the type $e^{-K_{L}\left(t-t_{a}\right)} ; 1 / K_{L}=2$ heart cycles; $t_{a}=3$ heart cycles. $\mathrm{c}=$ normal distribution: mean, 10 heart cycles; $\mathrm{SD}, 2$ heart cycles. $\mathrm{d}=$ frequency function of the type $e^{-K_{L}\left(t-t_{a}\right)} ; 1 / K_{L}$ $=5$ heart cycles; $t_{a}=6$ heart cycles. $t_{p}-\mathrm{T}_{\mathrm{RV}}=$ calculated pulmonary mean transit time. $\Delta=$ difference between calculated and imposed pulmonary mean transit time.

See Reconstruction of "left-heart" activity curves, Methods section, for explanation of numbers in parentheses.

changes in efficiency. The higher values for left atrial efficiency have been combined with the lower values for left ventricular efficiency, and vice versa, on the ground that enlargement of one chamber may cause displacement of the other, thus reducing its efficiency. Values of $W_{j}$ actually used are listed in Table I.

This table also contains the values for stroke volume, chamber size, and distribution of pulmonary transit times used in constructing left-heart time-activity curves. Chamber sizes have been selected to cover the range reported in the literature, in normal and pathologic conditions (16-20). Unfortunately, no data are presently available in the literature regarding the distribution of pulmonary transit times in man. Parrish, Hayden, Garrett, and Huff (21) have found in dogs that this distribution closely resembles the normal error curve in most instances, whereas Howard, Hamilton, and Dow (22) have obtained a skew curve, with the peak displaced to the left, in isolated perfused dog lungs. Since there is no basis for assuming a frequency function of pulmonary transit times with the peak displaced to the right, the normal distribution appears to be a limiting case in the sense that not more than one-half of the mass of the distribution may conceivably be located to the right of the mean value. Although the pulmonary circulation can- not be considered a mixing chamber, an exponential function of the type $e^{-K_{L}\left(t-t_{a}\right)}$, where $K_{L}$ is the rate constant of the pulmonary "mixing pool" and $t_{a}$ the transit time delay between the pulmonary artery and the left atrium, may be chosen to represent the limiting case with positive skewness for the frequency function of pulmonary transit times. Hence, the values of $p(t)$ used for calculations have been derived from normal distributions and from exponential functions of the type above. The actual parameters of these frequency functions are given in Table $I$. They have been selected on the basis of the following data: the dispersion of the left-heart activity curves recorded by precordial counting (e.g., Figure 1), the values of $t_{a}$ observed in man with precordial counting (20), and the values of $P M T T$ obtained in man by combined catheterization of the right and left hearts (1-4).

The solution of Equation 4 has been approximated by a system of algebraic equations such as

$$
\begin{aligned}
& C_{z p}(1)=C_{z}(1) p(1) \\
& C_{z p}(2)=C_{z}(2) p(1)+C_{z}(1) p(2), \cdots \\
& C_{z p}(t)=C_{z}(t) p(1)+C_{z}(t-1) p(2)+\cdots+C_{z}(1) p(t),
\end{aligned}
$$

where $t$ is made to vary from zero to 20 or 40 , by increments 


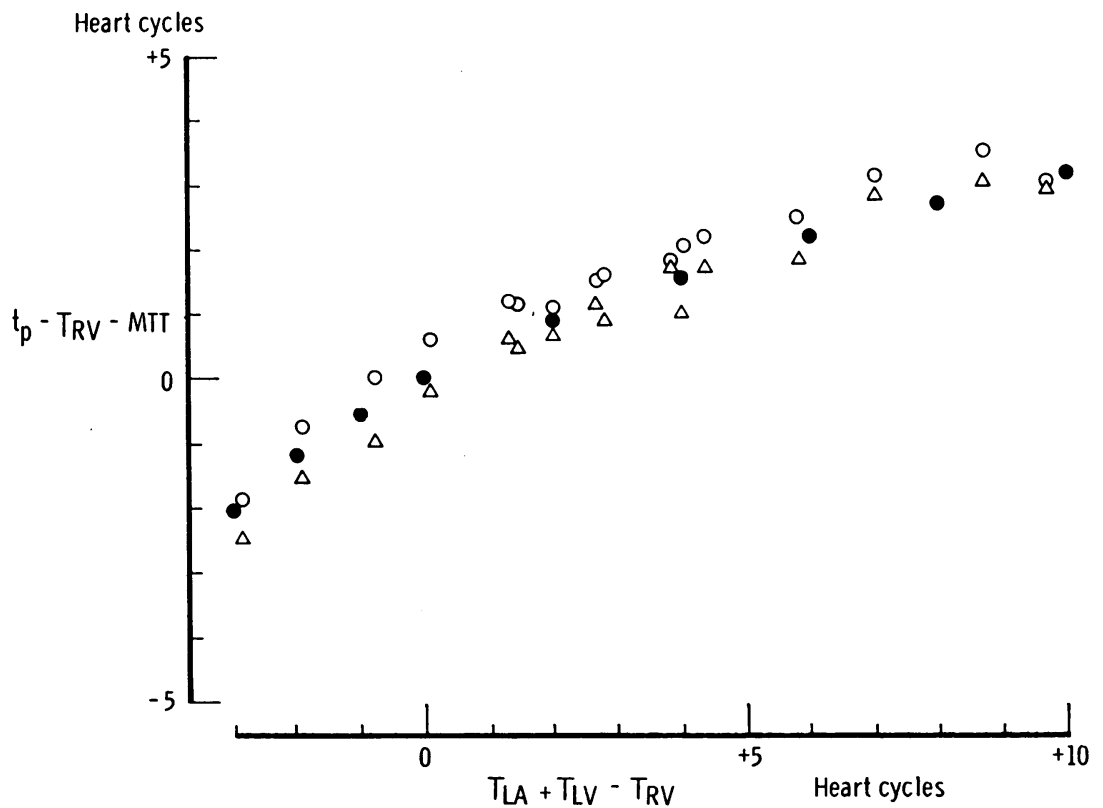

Fig. 4. A GRAPh RElating the difference between Calculated $\left(t_{p}-\mathrm{T}_{\mathrm{RV}}\right)$ AND IMPOSED (MTT) TRANSIT TIMES TO THE DIFFERENCE BETWEEN THE SUM $T_{\mathbf{L A}}+T_{\mathbf{L V}}$ AND $T_{\mathrm{RV}}$. The open circles represent values calculated assuming $a$ distribution of pulmonary transit times (Table I, distribution "c"). The triangles represent values calculated assuming a single pulmonary transit time. The difference between open circles and triangles, due to distribution "c," is always less than one heart cycle. The solid circles represent values calculated for a twochamber model with a single turnover time for the left heart $\left(T_{\mathbf{L B}}=T_{\mathbf{L A}}+T_{\mathbf{L V}}\right)$ and a single pulmonary transit time. No counting efficiency need be considered in this instance. The insignificant differences between closed circles and triangles show that with regard to the peak time of the left curve, the left heart can be treated as a single mixing chamber having a turnover time equal to the sum $T_{L \Delta}+$ T Lv.

of 0.1 and 0.2 heart cycles, respectively. Computation of this set of equations has been programmed for and performed on an IBM digital computer. ${ }^{1}$

Left atrial curves have been obtained from Equation 4 by introducing two exponential terms and a frequency function; left ventricular curves have been obtained with three exponential terms and the same frequency function. These concentration curves, each one multiplied by the corresponding effective volume, have been then summated to give the counting rate, $C R_{L H}(t)$, of the reconstructed "left precordial curve" as

$$
C R_{L H}(t)=W_{L A} C_{L A}(t)+W_{L V} C_{L V}(t) .
$$

Validity of the method as applied to reconstructed "leftheart" activity curves. The mean transit times calculated with Equation 2, $t_{p}-T_{R V}$, and the difference between these and the ones imposed are listed in Table I.

The error in $t_{p}-T_{R V}$ due to variations in size of the

1 Through the courtesy of the Watson Scientific Computing Laboratory of the International Business Machine Corporation, New_York, N. Y. chambers is plotted in Figure 4 (triangles) as a function of the difference between the sum of the turnover times of the left chambers, $T_{L A}+T_{L V}$, and the turnover time of the "right ventricle," $T_{R V}$. It can be seen that when $T_{L A}$ $+T_{L V}-T_{R V}$ varies from -3 to +10 heart cycles, the difference between the imposed and the calculated transit times varies from -2.5 to +3 heart cycles, respectively. A similar plot of the error in $t_{p}-T_{R V}$ for a two-chamber model, where $T_{L H}=T_{L A}+T_{L V}$, is represented in Figure 4 by solid circles. There is little difference between the solid circles and triangles, indicating that the presence of two mixing chambers rather than one in the left side of the model does not materially affect the position of the peak.

For any combination of volumes, the variations of counting efficiency of the "left atrium" and "left ventricle," given in Table I, do not significantly displace the peak of the left curve except when the volumes of both chambers are very large.

Displacement of the peak of the left curve may result from dispersion of pulmonary transit times when this dispersion is of the same order of magnitude or greater than that due to the mixing chambers; this displacement 
TABLE II

Pulmonary blood volume in 17 men without cardiovascular disease*

\begin{tabular}{|c|c|c|c|c|c|c|c|c|c|c|c|}
\hline $\begin{array}{l}\text { Subject } \\
\text { no. }\end{array}$ & Diagnosis & Age & BSA & TBV & $\mathrm{CO}$ & HR & SV & PMTT & PBV & PBV & $\frac{\mathrm{PBV}}{\mathrm{TBV}} \times 100$ \\
\hline & & years & $m^{2}$ & $m l / m^{2}$ & $L / \min / m^{2}$ & $\begin{array}{l}\text { beats/ } \\
\text { min }\end{array}$ & $m l$ & $\begin{array}{l}\text { heart } \\
\text { cycles }\end{array}$ & $m l$ & $m l / m^{2}$ & $\%$ \\
\hline 1,216 & Pulm. tbc, MA & 48 & 1.75 & & 4.42 & 74 & 104 & 5.9 & 608 & 347 & \\
\hline 1,218 & Acute rheumatic fever & 24 & 1.85 & & $3.57 \mathrm{~F}$ & 52 & 127 & 5.0 & 639 & 345 & \\
\hline 1,221 & Pulm. tbc, MA & 24 & 1.79 & & 5.23 & 76 & 123 & 5.3 & 657 & 367 & \\
\hline 1,224 & Resolving pneumonia & 49 & 1.86 & 2,923 & 3.98 & 72 & 103 & 6.8 & 694 & 373 & 12.8 \\
\hline 1,227 & Pulm. tbc, $\mathbf{M}$ & 48 & 1.65 & & 4.78 & 83 & 95 & 5.8 & 550 & 333 & \\
\hline 1,250 & Pulm. tbc, FA & 40 & 1.80 & 2,911 & 3.97 & 93 & 77 & 6.7 & 512 & 284 & 9.8 \\
\hline 1,253 & Pulm. tbc, FA & 59 & 1.53 & 2,487 & 3.14 & 69 & 70 & 4.6 & 318 & 208 & 8.4 \\
\hline 1,255 & Bronch. CA & 40 & 1.98 & 3,104 & 4.38 & 80 & 108 & 6.2 & 665 & 336 & 10.8 \\
\hline 1,256 & Pleural thickening & 56 & 1.71 & 2,968 & 4.13 & 87 & 81 & 5.3 & 433 & 253 & 8.5 \\
\hline 1,259 & Pulm. tbc, MA & 53 & 1.60 & 2,113 & 2.72 & 64 & 68 & 5.8 & 392 & 245 & 11.6 \\
\hline 1,261 & Healed miliary tbc & 32 & 1.78 & 2,757 & 3.47 & 73 & 85 & 5.7 & 486 & 273 & 9.9 \\
\hline 1,323 & Resolving pneumonia & 51 & 1.88 & 3,065 & 4.54 & 92 & 93 & 5.7 & 530 & 282 & 9.2 \\
\hline 1,326 & Resolving pneumonia & 36 & 1.85 & 2,797 & 3.86 & 71 & 101 & 5.8 & 588 & 318 & 11.4 \\
\hline 1,327 & Resolving pneumonia & 41 & 1.86 & 2,974 & 3.85 & 80 & 90 & 5.5 & 496 & 267 & 9.0 \\
\hline 1,336 & Bronch. CA & 74 & 1.76 & 2,688 & 3.25 & 85 & 67 & 6.9 & 460 & 261 & 9.7 \\
\hline 1,346 & Resolving pneumonia & 46 & 1.60 & 2,651 & 2.71 & 77 & 56 & 7.0 & 393 & 246 & 9.3 \\
\hline 1,357 & Resolving pneumonia & 46 & 1.66 & 2,580 & $4.05^{F}$ & 89 & 77 & 5.3 & 403 & 243 & 9.4 \\
\hline $\mathrm{n}$ & & 17 & 17 & 13 & 17 & 17 & 17 & 17 & 17 & 17 & 13 \\
\hline Mean & & 45.1 & 1.76 & 2,771 & 3.89 & 77 & 90 & 5.8 & 519 & 293 & 10.0 \\
\hline $\mathrm{SD}$ & & 12.5 & 0.12 & 273 & 0.47 & 11 & 20 & 0.7 & 111 & 50 & 1.3 \\
\hline
\end{tabular}

* Pulm. $\mathrm{tbc}=$ pulmonary tuberculosis; $\mathrm{MA}=$ moderately advanced, $\mathrm{M}=$ minimal, $\mathrm{FA}=$ far advanced. Bronch. $\mathrm{CA}=\mathrm{bronchogenic}$ car cinoma. Miliary tbc $=$ miliary tuberculosis. $\mathrm{CO}=$ cardiac output, TBV $=$ total blood volume, $\mathrm{HR}=$ heart rate, $\mathrm{SV}=\mathrm{stroke}$ volume, PMTT $=$ pulmonary mean transit time, $\mathrm{PBV}=$ pulmonary blood volume, and $\mathrm{F}=$ cardiac output obtained by Fick method.

depends on the form of the frequency function chosen to represent the pulmonary transit times. The dispersions of normal distributions "a" and "c" (Table I) appear to have little effect on the position of the peak of the left curve for all the combinations of chamber volumes listed in Table I. Figure 4, where the values represented by triangles have been calculated without any dispersion and those plotted as open circles contain distribution "c," illustrates that $t_{p}-T_{R V}$ tends to overestimate $P M T T$ in the case of normal distributions. With delayed exponentials of the type $e^{-K_{L}\left(t-t_{a}\right)}$ as frequency functions in a model consisting of two equal mixing chambers, $t_{p}-T_{R V}$ yields an exact value of $P M T T$ only when $K_{L}$ is equal to the rate constant of the chambers, $K_{H}$. Good approximations of $P M T T$, however, are given by $t_{p}-T_{R V}$ even when $K_{L}$ is widely divergent from $K_{H} ; t_{p}-T_{R V}$ will tend to overestimate or underestimate $P M T T$, depending on whether $K_{L}$ is greater or smaller than $K_{H}$.

\section{Technique}

The details of the technique for obtaining radiocardiograms have already been published (23). Only some points of interest and a few modifications are described here. The tip of a cardiac catheter is placed either in the right atrium in front of the tricuspid valve, or in the inflow tract of the right ventricle. The catheter is filled with a solution containing about $80 \mu \mathrm{c}$ of radioiodinated ( $\left.{ }^{131}\right)$ human serum albumin (RISA) ${ }^{2}$ and 10 U.S.P. U of heparin per $\mathrm{ml}$. The latter is added to prevent clotting between successive injections. A semiautomatic syringe set to deliver $0.5 \mathrm{ml}$

\footnotetext{
2 Abbott Laboratories, North Chicago, Ill.
}

and connected to a reservoir syringe is used for injecting. Injections are performed manually to coincide with the $T$ wave of the electrocardiogram. The injection time is usually shorter than one heart cycle.

During the introduction of the catheter, the projection of the tricuspid valve is marked on the chest wall. The collimator is then located immediately to the left of the mark. This location is usually at the level of the fourth intercostal space between the midline and the left sternal border.

Blood samples are withdrawn and precordial counting rates recorded before and after each curve to determine the calibration factor necessary for the calculation of the cardiac output. Blood samples utilized to measure total blood volume are drawn at least 5 minutes after injection of RISA. The peripheral hematocrit is corrected for trapped plasma and then converted to body hematocrit according to Chaplin, Mollison, and Vetter (24). In patients of this series who were given Tris, ${ }^{3}$ the technique was somewhat modified: the blood volume was deterimned from the dilution of both RISA and T-1824, injected and sampled independently, and an equilibration period of 10 to 20 minutes allowed for T-1824. Since in these cases the total blood volume calculated from $\mathrm{T}-1824$ dilution did not differ by more than $10 \%$ from that determined by RISA, only the data calculated from the latter appear in Tables II through V.

The recorded tracings are read every 0.1 second and corrected for rate-meter damping (25). The corrected values are averaged for each heart cycle and plotted on semi-

\footnotetext{
${ }^{3}$ Courtesy of the Sigma Chemical Co., St. Louis. Mo.
} 
TABLE III

Pulmonary blood volume in 7 men with chronic bronchitis and emphysema*

\begin{tabular}{|c|c|c|c|c|c|c|c|c|c|c|}
\hline $\begin{array}{c}\text { Subject } \\
\text { no. }\end{array}$ & Age & BSA & T BV & $\begin{array}{l}\text { Cardiac } \\
\text { output }\end{array}$ & HR & SV & PMTT & PBV & PBV & $\frac{\mathrm{PBV}}{\mathrm{TBV}} \times 100$ \\
\hline & years & $m^{2}$ & $m l / m^{2}$ & $L / \min / m^{2}$ & $\begin{array}{c}\text { beats / } \\
\text { min }\end{array}$ & $m l$ & $\begin{array}{l}\text { heart } \\
\text { cycles }\end{array}$ & $m l$ & $m l / m^{2}$ & $\%$ \\
\hline $\begin{array}{l}1,276 \\
1,285 \\
1,289 \\
1,291 \\
1,298 \\
1,303 \\
1,312\end{array}$ & $\begin{array}{l}48 \\
53 \\
62 \\
57 \\
53 \\
64 \\
72\end{array}$ & $\begin{array}{l}1.60 \\
1.63 \\
1.94 \\
1.59 \\
1.54 \\
1.68 \\
1.75\end{array}$ & $\begin{array}{l}2,523 \\
2,702 \\
3,352 \\
2,436 \\
2,576 \\
2,613 \\
2,359\end{array}$ & $\begin{array}{l}3.73 \\
3.89 \\
3.41 \\
2.68 \\
2.82 \\
2.23 \\
2.70\end{array}$ & $\begin{array}{r}113 \\
92 \\
69 \\
63 \\
102 \\
77 \\
71\end{array}$ & $\begin{array}{l}53 \\
69 \\
96 \\
67 \\
43 \\
49 \\
66\end{array}$ & $\begin{array}{l}8.2 \\
8.1 \\
5.8 \\
5.8 \\
8.0 \\
8.6 \\
7.1\end{array}$ & $\begin{array}{l}434 \\
560 \\
561 \\
388 \\
340 \\
423 \\
473\end{array}$ & $\begin{array}{l}271 \\
344 \\
289 \\
244 \\
221 \\
252 \\
270\end{array}$ & $\begin{array}{r}10.8 \\
12.7 \\
8.6 \\
10.0 \\
8.6 \\
9.6 \\
11.5\end{array}$ \\
\hline Mean & 58.4 & 1.68 & 2,652 & 3.07 & 84 & 63 & 7.4 & 454 & 270 & 10.3 \\
\hline $\mathrm{SD}$ & 8.1 & 0.14 & 328 & 0.62 & 19 & 18 & 1.2 & 83 & 39 & 1.5 \\
\hline
\end{tabular}

* Abbreviations as in Table II.

logarithmic paper. After subtraction of the extrapolated values of the right curve, the left curve is plotted on linear paper and interpolated to give a smooth curve. The peak time of this curve, $t_{p}$, is read on the abscissa, which is timed from the moment of injection.

The time from injection to the onset of the washout of the right ventricle, $t_{0}$, is added to the turnover time of the right ventricle, $T$, to give the mean injection time $T^{\prime}$ of tracer into the pulmonary circulation. Therefore, the pulmonary blood volume is obtained as

$$
\mathrm{PBV}=\mathrm{SV}\left(t_{p}-T^{\prime}\right)
$$

In most instances, simultaneous determinations of cardiac output were made by RISA radiocardiography and the direct Fick method. The latter has not been used for calculating PBV except when the calibration factor for the radiocardiogram could not be secured.

\section{Patients}

Twenty determinations of PBV were made in 17 patients with normal cardiovascular systems (Tables II and
IX). The diagnoses and physical characteristics are given in Table II. Ten determinations were made in seven patients with chronic bronchitis and emphysema (Tables III and IX). Twelve determinations were made in nine patients with cor pulmonale (Tables IV and IX); eight of these had chronic bronchitis and emphysema; the remaining one had diffuse interstitial pulmonary fibrosis and a right 7 rib thoracoplasty for tuberculosis (no. 1,184). One patient (no. 1,238) had evidence of right ventricular failure at the time of study, one had never been in failure (no. 1,352), whereas the remainder had all had previous evidence of right ventricular failure. Eleven determinations were obtained in seven patients with various other types of heart disease (Tables V and IX).

All measurements were made at rest, on recumbent patients in the postabsorptive state, with no premedication. In five normal subjects, studies were repeated during a period of mild leg exercise (Table VI), and in four other normal patients, during and after infusion of sodium bicarbonate solution (Table VII). Eight patients with

TABLE IV

Pulmonary blood volume in 9 patients with cor pulmonale*

\begin{tabular}{|c|c|c|c|c|c|c|c|c|c|c|c|}
\hline $\begin{array}{c}\text { Subject } \\
\text { no. }\end{array}$ & Sex & Age & BSA & T BV & $\begin{array}{l}\text { Cardiac } \\
\text { output }\end{array}$ & HR & SV & PMTT & PBV & PBV & $\frac{\text { PBV }}{\text { TBV }} \times 100$ \\
\hline & & years & $m^{2}$ & $m l / m^{2}$ & $L / \min / m^{2}$ & $\begin{array}{l}\text { beats/ } \\
\text { min }\end{array}$ & $m l$ & $\begin{array}{l}\text { heart } \\
\text { cycles }\end{array}$ & $m l$ & $m l / m^{2}$ & $\%$ \\
\hline 1,179 & $\underset{\mathrm{M}}{\mathrm{M}}$ & $\begin{array}{l}57 \\
32\end{array}$ & 1.65 & 3,253 & $\begin{array}{l}3.00 \\
3.37\end{array}$ & 98 & $\begin{array}{l}51 \\
45\end{array}$ & 11.2 & 572 & 347 & 10.7 \\
\hline $\begin{array}{l}1,184 \\
1223\end{array}$ & $\begin{array}{l}\mathrm{F} \\
\mathbf{M}\end{array}$ & $\begin{array}{l}32 \\
59\end{array}$ & $\begin{array}{l}1.53 \\
1.71\end{array}$ & 3.612 & $\begin{array}{l}3.37 \\
274\end{array}$ & 115 & $\begin{array}{l}45 \\
81\end{array}$ & 9.0 & 405 & 265 & $12 ?$ \\
\hline 1,238 & M & $\begin{array}{l}59 \\
55\end{array}$ & $\begin{array}{l}1.11 \\
2.18\end{array}$ & $\begin{array}{l}3,012 \\
3,176\end{array}$ & $\begin{array}{l}2.74 \\
3.54\end{array}$ & $\begin{array}{l}58 \\
86\end{array}$ & $\begin{array}{l}81 \\
90\end{array}$ & $\begin{array}{l}9.4 \\
5.5\end{array}$ & $\begin{array}{l}759 \\
499\end{array}$ & $\begin{array}{l}444 \\
229\end{array}$ & $\begin{array}{r}12.3 \\
7.2\end{array}$ \\
\hline 1,319 & $\mathbf{M}$ & 71 & 1.88 & 3,561 & 2.80 & 59 & 88 & 6.9 & 617 & 328 & 9.2 \\
\hline 1,322 & $\mathbf{M}$ & 59 & 1.57 & 3,006 & 2.41 & 77 & 49 & 9.2 & 451 & 287 & 9.6 \\
\hline 1,351 & $\mathbf{M}$ & 59 & 1.73 & 3,357 & 3.02 & 83 & 63 & 8.8 & 554 & 320 & 9.5 \\
\hline 1,352 & $\mathbf{M}$ & 42 & 2.03 & 3,891 & 4.27 & 63 & 138 & 5.9 & 807 & 398 & 10.2 \\
\hline 1,367 & $\mathbf{M}$ & 60 & 1.82 & 3,199 & 3.20 & 85 & 69 & 9.8 & 679 & 373 & 11.7 \\
\hline $\mathbf{n}$ & & 9 & 9 & 8 & 9 & 9 & 9 & 9 & 9 & 9 & 8 \\
\hline Mean & & 54.9 & 1.79 & 3,382 & 3.15 & 80 & 75 & 8.4 & 594 & 332 & 10.1 \\
\hline $\mathrm{SD}$ & & 11.3 & 0.21 & 288 & 0.54 & 19 & 29 & 1.9 & 136 & 67 & 1.6 \\
\hline
\end{tabular}

* Abbreviations as in Table II. 
TABLE V

Pulmonary blood volume in 7 men with various types of heart disease*

\begin{tabular}{|c|c|c|c|c|c|c|c|c|c|c|c|}
\hline $\begin{array}{c}\text { Subject } \\
\text { no. }\end{array}$ & Diagnosis & Age & BSA & TBV & $\begin{array}{l}\text { Cardiac } \\
\text { output }\end{array}$ & HR & sv & PMTT & PBV & PBV & $\frac{\mathrm{PBV}}{\mathrm{TBV}} \times 100$ \\
\hline & & years & $m^{2}$ & $m l / m^{2}$ & $L / \min / m^{2}$ & $\begin{array}{c}\text { beats/ } \\
\text { min }\end{array}$ & $m l$ & $\begin{array}{l}\text { heart } \\
\text { cycles }\end{array}$ & $m l$ & $m l / m^{2}$ & $\%$ \\
\hline 1,182 & Calcific pericarditis, AF & 68 & 1.90 & & 2.99 & 68 & 84 & 10.3 & 869 & 457 & \\
\hline 1,208 & $\begin{array}{l}\text { ASHD, EH, complete } \\
\text { a-v dissociation }\end{array}$ & 72 & 1.85 & 2,807 & 3.11 & 39 & 149 & 4.9 & 726 & 392 & 14.0 \\
\hline 1,262 & $\begin{array}{l}\text { Unknown heart disease, } \\
\text { EH, AF, LVF }\end{array}$ & 70 & 1.92 & 3,631 & 3.61 & 43 & 162 & 6.4 & 1,037 & 540 & 14.9 \\
\hline 1,263 & RHD, MS, At. flutter & 50 & 1.85 & 2,994 & 2.52 & 90 & 52 & 9.1 & 471 & 255 & 8.5 \\
\hline 1,316 & $\begin{array}{c}\text { HCVD, EH, NSR, } \\
\text { CHF }\end{array}$ & 67 & 1.49 & 2,488 & 1.50 & 106 & 21 & 17.6 & 370 & 248 & 10.0 \\
\hline 1,338 & $\begin{array}{l}\text { HCVD, EH, NSR, } \\
\text { LVF }\end{array}$ & 64 & 1.71 & 3,126 & 3.11 & 97 & 55 & 15.3 & 840 & 491 & 15.7 \\
\hline 1,353 & $\underset{\text { CHF }}{\text { ASHD, EH, AS, NSR, }}$ & 68 & 1.89 & 2,696 & 2.44 & 87 & 53 & 14.5 & 770 & 407 & 15.1 \\
\hline
\end{tabular}

* ASHD = arteriosclerotic heart disease, RHD = rheumatic heart disease, HCVD = hypertensive cardiovascular disease, $\mathrm{EH}=$ enlarged heart, $\mathrm{MS}=$ mitral stenosis, $\mathrm{AS}=$ aortic stenosis, $\mathrm{AF}=$ atrial fibrillation, At. flutter = atrial flutter, NSR = normal sinus rhythm, CHF = congestive heart failure, and LVF = left ventricular failure.

chronic bronchitis and emphysema, with and without cor pulmonale, were studied during an infusion of Tris (Table VIII).

\section{RESULTS}

The results obtained at rest in cardiovascular normal subjects, in patients with chronic bronchitis and emphysema, and in patients with cor pulmonale are listed in Tables II, III, and IV. The average $\mathrm{PBV}$ in normal subjects was found to be $519 \pm 111 \mathrm{ml}$, corresponding to $293 \pm 50 \mathrm{ml}$ per $\mathrm{m}^{2} \mathrm{BSA}$. In patients with chronic bronchitis and emphysema the mean values were $454 \pm 83 \mathrm{ml}$, and $270 \pm 39 \mathrm{ml}$ per $\mathrm{m}^{2}$. Values of $594 \pm 136$ $\mathrm{ml}$ and $332 \pm 67 \mathrm{ml} \mathrm{m}^{2}$ were obtained in patients with cor pulmonale. Table $\mathrm{V}$ presents results obtained in patients with heart diseases other than cor pulmonale. Owing to the heterogeneity of this group, no average values have been calculated.

In the normal group, a significant positive correlation has been found between $\mathrm{PBV}$ and $\mathrm{BSA}$, total blood volume, cardiac output, and stroke volume (Figure 5). The correlation coefficients and their $t$ values are : $r=0.842 \pm 0.139$ and $t=$ 6.04 for $\mathrm{PBV}$ and $\mathrm{BSA} ; r=0.814 \pm 0.175$ and $t$ $=4.65$ for $\mathrm{PBV}$ and total blood volume; $r=0.762$ \pm 0.167 and $t=4.56$ for PBV and cardiac output; and $r=0.881 \pm 0.122$ and $t=7.20$ for $\mathrm{PBV}$ and

TABLE VI

Pulmonary blood volume in 5 normal men at rest and during exercise*

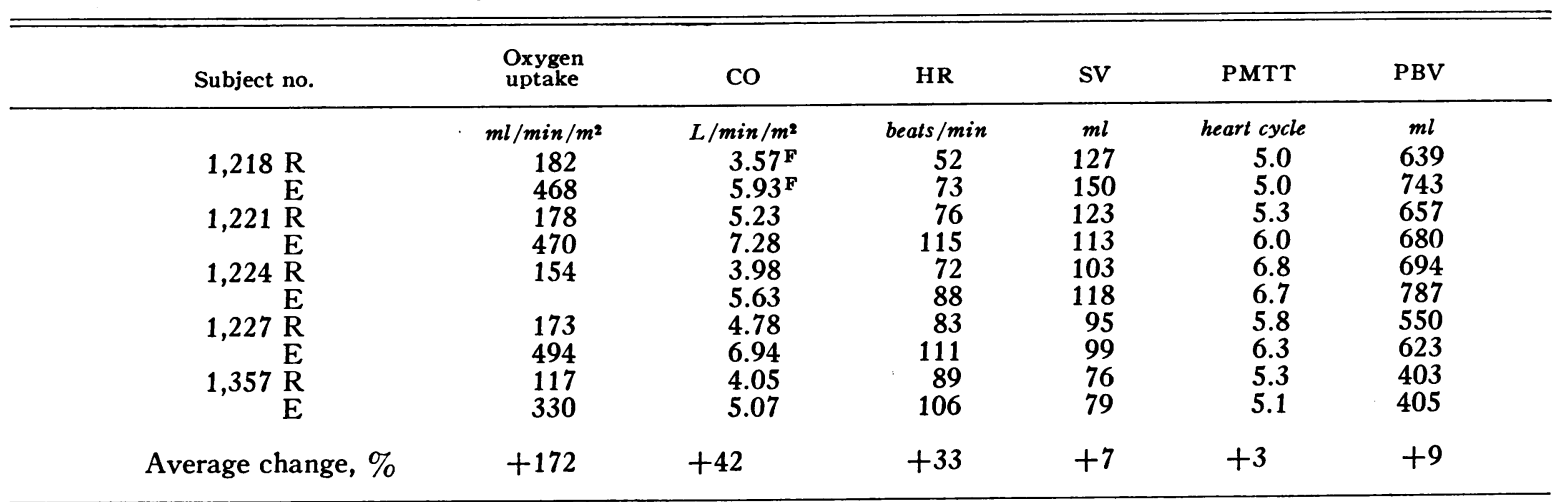

* Abbreviations as in Table $\mathrm{II}$, and $\mathrm{R}=$ at rest, and $\mathrm{E}=$ during exercise. 
TABLE VII

Pulmonary blood volume in 4 normal subjects during an infusion of sodium bicarbonate*

\begin{tabular}{|c|c|c|c|c|c|c|}
\hline Subject no. & Condition & $\mathrm{CO}$ & HR & sv & PMTT & PBV \\
\hline & & $L / \min / m^{2}$ & beats/min & $m l$ & $\begin{array}{l}\text { heart } \\
\text { cycles }\end{array}$ & $m l$ \\
\hline \multirow[t]{2}{*}{1,250} & Control & $\begin{array}{l}3.97 \\
4.00\end{array}$ & $\begin{array}{l}93 \\
94\end{array}$ & $\begin{array}{l}77 \\
77\end{array}$ & $\begin{array}{l}6.7 \\
6.9\end{array}$ & $\begin{array}{l}512 \\
530\end{array}$ \\
\hline & Infusion: $3 \mathrm{~min}$ & 4.44 & 93 & 86 & 6.7 & 577 \\
\hline \multirow[t]{5}{*}{1,253} & Control & 3.14 & 69 & 70 & 4.6 & 318 \\
\hline & Infusion: $1 \mathrm{~min}$ & 2.87 & 73 & 60 & 5.3 & 315 \\
\hline & $2 \min$ & 2.97 & 70 & 65 & 4.9 & 321 \\
\hline & $3 \mathrm{~min}$ & 3.22 & 71 & 70 & 5.1 & 355 \\
\hline & $12 \mathrm{~min}$ & 5.11 & 85 & 92 & 5.4 & 497 \\
\hline \multirow[t]{5}{*}{1,255} & Control & 4.38 & 80 & 108 & 6.2 & 665 \\
\hline & Infusion: $4 \mathrm{~min}$ & 4.50 & 76 & 117 & 5.6 & 656 \\
\hline & $6 \mathrm{~min}$ & 5.33 & 81 & 130 & 5.6 & 723 \\
\hline & $11 \mathrm{~min}$ & 6.10 & 87 & 139 & 5.2 & 730 \\
\hline & After infusion: $6 \mathrm{~min}$ & 6.58 & 88 & 148 & 5.5 & 810 \\
\hline \multirow[t]{6}{*}{1,256} & Control & 4.13 & 87 & 81 & 5.3 & 433 \\
\hline & Infusion: $5 \mathrm{~min}$ & 4.23 & 79 & 92 & 5.3 & 488 \\
\hline & $7 \mathrm{~min}$ & 4.30 & 81 & 91 & 5.2 & 475 \\
\hline & $11 \mathrm{~min}$ & 5.34 & 89 & 103 & 5.0 & 511 \\
\hline & After infusion : $10 \mathrm{~min}$ & 5.23 & 90 & 100 & 5.3 & 531 \\
\hline & $13 \mathrm{~min}$ & 5.47 & 82 & 114 & 4.9 & 563 \\
\hline Average change, $\%$ & & +39 & +7 & +30 & 0 & +30 \\
\hline
\end{tabular}

* Abbreviations as in Table II.

stroke volume. All these correlations are highly significant $(p<0.001)$.

The relationship between PBV and stroke volume in patients with emphysema, cor pulmonale, and various types of heart disease is presented in Figure 6. A correlation of PBV with stroke volume is observed in the series of 23 patients with emphysema, cor pulmonale, and various other forms of heart disease. The significance of the correlation, however, is reduced $(r=0.554,0.01$ $>\mathrm{p}>0.001)$, and the relationship between PBV and stroke volume is different from that observed in normal subjects. Only in 5 of the 23 patients does this relationship fall within $1 \mathrm{SD}$ of the regression line for normal subjects. In these patients, as well as in normal subjects, the correlation between $\mathrm{PBV}$ and stroke volume is significant to a higher degree than that between $\mathrm{PBV}$ and cardiac output $(r=0.498,0.02>p>0.01)$.

In spite of the differences in PBV between normal subjects and patients with emphysema or cor pulmonale, the ratio of $\mathrm{PBV}$ to total blood volume remains remarkably constant in these three groups, being $10.0 \pm 1.3 \%$ in cardiovascular normal subjects, $10.3 \pm 1.5 \%$ in patients with chronic bronchitis and emphysema, and $10.1 \pm 1.6 \%$ in patients with cor pulmonale. In patients with other forms of heart disease, this ratio is variable and in this study attained a maximum of $15.7 \%$.

Table VI lists the data obtained in five normal subjects at rest and during exercise. In four of these subjects, measurements were made after minute 5 of exercise; in one (no. 1224), measurements were made during minute 2 of exercise. The increase in PBV observed at this level of exercise is of doubtful significance and, on the average, parallels changes in stroke volume; on the other hand, the cardiac index rose considerably, the increase averaging $42 \%$.

A rise in cardiac output of the same order of magnitude was produced in four normal subjects by an infusion of sodium bicarbonate solution. Data from these studies obtained both during and after infusion are listed in Table VII and show 
an increase of $\mathrm{PBV}$ and stroke volume paralleling in time and degree the change in cardiac index.

In Table VIII are reported the results observed in patients with chronic bronchitis and emphysema, with and without cor pulmonale, during an infusion of Tris. Only the control values and those corresponding to the highest cardiac index have been tabulated. The average changes in cardiac output, stroke volume, and PBV are of the same order of magnitude. The average PMTT measured in heart cycles does not show any appreciable variation during either exercise or infusion of sodium bicarbonate or Tris.

The reproducibility of the PBV obtained with the method described has been examined in a group of 13 subjects. Two determinations of PBV have been carried out in each of these subjects in basal conditions at an interval of about 3 minutes. The results are reported in Table IX. The mean of the first determinations does not differ significantly from the mean of the second $(p>$ $0.90)$. The average percentile difference between the first and second of the duplicate measurements, regardless of sign, was 5.5 , ranging from 0.5 to 15.5.

\section{DISCUSSION}

The method. The conditions required for all applications of the dilution principle to the measurement of volume of blood circulating through a vascular section are: that complete mixing between indicator and blood be achieved at the entrance to the section; that the system be in a steady state; and that the entrance and the exit of the section be accessible to injection or sampling.

When an indicator is injected directly into the pulmonary artery, the extent of mixing between indicator and blood cannot be ascertained, and the assumption that the circulation time of the tracer is representative of the circulation time of the blood has to be made. There is evidence that the interposition of the right ventricle between the point of injection and the pulmonary circulation assures satisfactory mixing between the indicator and circulating blood, since it is possible to measure right ventricular output by sampling in the pulmonary

TABLE VIII

Pulmonary blood volume during an infusion of Tris*

\begin{tabular}{|c|c|c|c|c|c|c|}
\hline Subject no. & Condition & $\mathrm{CO}$ & HR & sv & PMTT & PBV \\
\hline \multirow[t]{2}{*}{1,291} & Control & $\begin{array}{c}L / \min / m^{2} \\
2.68\end{array}$ & $\begin{array}{c}\text { beats } / \text { min } \\
63\end{array}$ & $\begin{array}{c}m l \\
67\end{array}$ & $\begin{array}{c}\text { heart cycles } \\
5.8\end{array}$ & $\begin{array}{l}m l \\
388\end{array}$ \\
\hline & Infusion: $11 \mathrm{~min}$ & 4.09 & 75 & 87 & 5.4 & 474 \\
\hline \multirow[t]{2}{*}{1,298} & Control & $\begin{array}{l}2.82 \\
2.93\end{array}$ & $\begin{array}{l}102 \\
104\end{array}$ & $\begin{array}{l}43 \\
43\end{array}$ & $\begin{array}{l}8.0 \\
8.4\end{array}$ & $\begin{array}{l}340 \\
363\end{array}$ \\
\hline & Infusion: $9 \mathrm{~min}$ & 4.01 & 114 & 54 & 7.9 & 427 \\
\hline \multirow[t]{2}{*}{1,303} & Control & 2.23 & 77 & 49 & 8.6 & 423 \\
\hline & Infusion : $11 \mathrm{~min}$ & 3.01 & 85 & 60 & 8.5 & 506 \\
\hline \multirow[t]{2}{*}{1,312} & Control & 2.70 & 71 & 66 & 7.1 & 473 \\
\hline & Infusion: $4 \mathrm{~min}$ & 3.58 & 74 & 84 & 8.1 & 677 \\
\hline \multirow[t]{2}{*}{1,319} & Control & 2.80 & 59 & 90 & 6.9 & 617 \\
\hline & Infusion: $4 \mathrm{~min}$ & 3.16 & 58 & 103 & 7.7 & 796 \\
\hline \multirow[t]{2}{*}{1,322} & Control & 2.41 & 77 & 49 & 9.2 & 451 \\
\hline & Infusion : $12 \mathrm{~min}$ & 3.08 & 80 & 61 & 8.9 & 542 \\
\hline \multirow[t]{2}{*}{1,351} & Control & $\begin{array}{l}3.02 \\
2.67\end{array}$ & $\begin{array}{l}83 \\
85\end{array}$ & $\begin{array}{l}63 \\
54\end{array}$ & $\begin{array}{l}8.8 \\
9.8\end{array}$ & $\begin{array}{l}554 \\
531\end{array}$ \\
\hline & Infusion: $12 \mathrm{~min}$ & 3.72 & 95 & 68 & 10.3 & 702 \\
\hline \multirow[t]{2}{*}{1,352} & Control & $\begin{array}{l}4.27 \\
4.34\end{array}$ & $\begin{array}{l}63 \\
64\end{array}$ & $\begin{array}{l}138 \\
138\end{array}$ & $\begin{array}{l}5.9 \\
5.6\end{array}$ & $\begin{array}{l}807 \\
778\end{array}$ \\
\hline & Infusion: $12 \mathrm{~min}$ & 6.01 & 78 & 156 & 5.8 & 902 \\
\hline Average change, $\%$ & & +34 & +11 & +21 & +4 & +25 \\
\hline
\end{tabular}

* Abbreviations as in Table II. Patients had chronic bronchitis and emphysema, with and without cor pulmonale. 

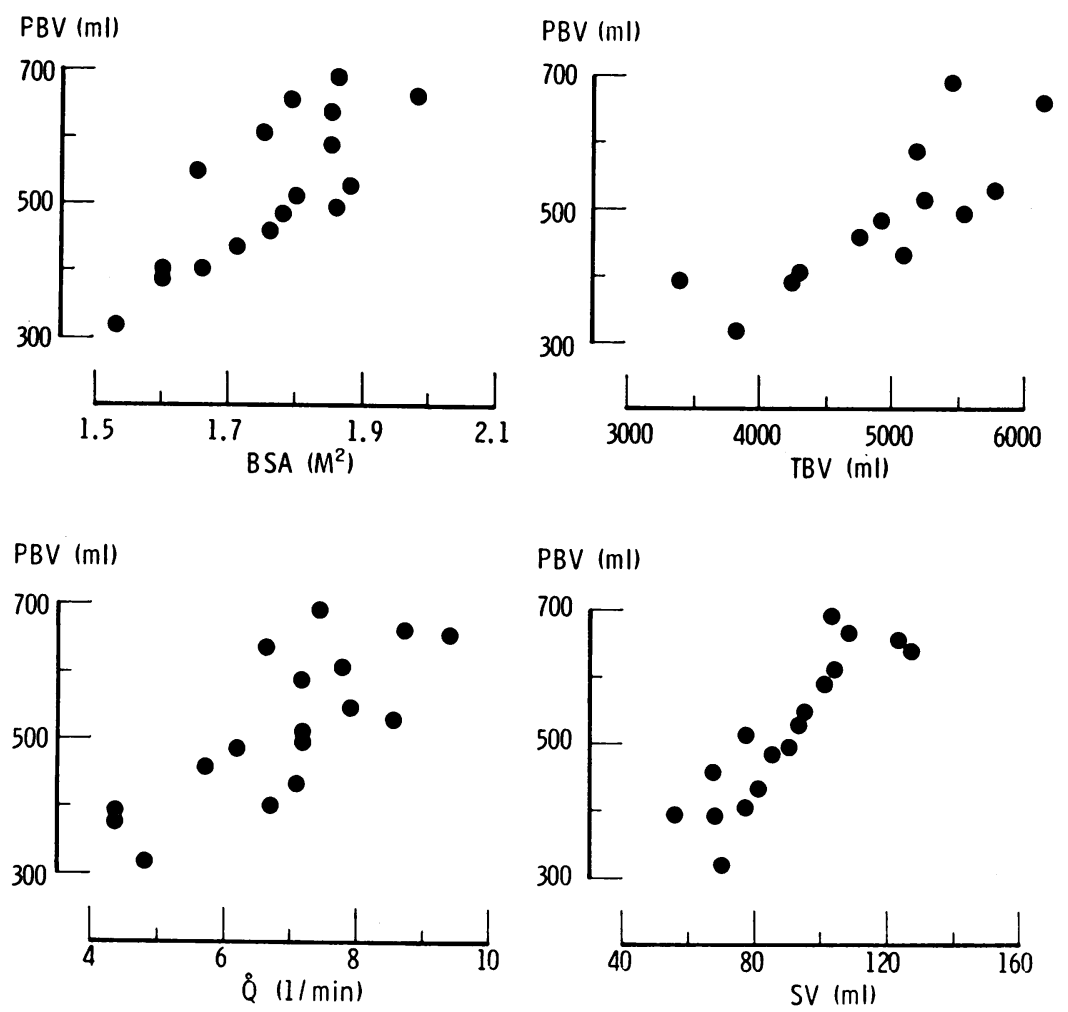

Fig. 5. VAlues of PUlmonary blood volume obtained IN 17 NORMal sUbJECTS ARE PLOTTED AGAINST BODY SURFACE AREA (PBV $=-708+698$ BSA), TOTAL BLOOD VOLUME (PBV $=-61+0.112$ TBV), CARDIAC OUTPUT ( $\mathrm{PBV}=$ $123+58 \dot{Q})$, AND STROKE VOLUME $(\mathrm{PBV}=77+5 \mathrm{SV})$.

artery after single injection or constant infusion of indicator in the right atrium $(26,27)$. Further evidence is provided by experiments in dogs that show a uniform distribution of microspheres per gram of lung tissue after their injection into the jugular vein (28).

Since blood flow is intermittent, thus causing periodic variations in the volume of blood present in the pulmonary circulation, the requirements that the rate of flow and the volume of the section remain constant are not strictly met. In principle, the volume determined by multiplying the stroke volume by the mean circulation time is close to, but does not necessarily coincide with, the arithmetic mean of the maximal and minimal PBV.

With the present method, determination of $\mathrm{PBV}$ in changing states is valid only if during the time of inscription of the entire curve no significant variations occur in any of the hemodynamic characteristics of the system. In other words, the rate of change of the parameters of the system must be much lower than the rate at which the two sides of the heart empty and the rate at which the pulmonary circulation transfers the indicator. Significant hemodynamic variations in the central circulation taking place in a few seconds cannot be followed by this technique.

The anatomic limits, and therefore, the physiologic meaning of the volume of blood measured by the method described, may not be exactly the same in different hemodynamic situations. While the limit of the measured volume with regard to the right heart is defined by the pulmonary valve, the limit with regard to the left heart is somewhat illdefined because of the complex origins of the left peak. This limit usually lies somewhere in the left atrium.

The assumption that the left atrium is a mixing chamber and disperses indicator in a manner similar to that of the ventricle demands some discussion. Incomplete mixing in the left atrium would reduce the dilution of label, and the peak of the 
left curve would occur earlier than expected on the basis of the volume of the chamber. If the left atrium does not behave like a ventricle, since for a period of the heart cycle, blood flows into and out of the chamber at the same time, the dilution of label will be greater than that occurring in a ventricle with the same maximal volume. It is practically impossible to assess the extent to which these opposite effects influence the dilution of label, but errors stemming from them should tend to cancel each other.

Results of the model analysis indicate that only small over- or underestimations of PBV arise from dispersions of pulmonary transit times that are compatible with recorded curves. Overestimation of the pulmonary mean transit time may be due to the sum of the turnover times of the leftheart chambers being usually greater than the turnover time of the right ventricle. The overestimation expected in normal subjects on the basis of normal figures for cardiac output and vol- umes of the heart cavities does not exceed one stroke volume. In patients with heart disease and predominant enlargement of either one or both left chambers, PBV may be overestimated by as much as the equivalent of three stroke volumes if the volume of the left chambers exceeds that of the right ventricle by ten times the stroke volume. This situation approaches the limits of useful application of the method, since left curves expected and obtained from extremely large cardiac chambers do not present a distinct peak and hence are not analyzable.

When the cardiac enlargement is predominantly on the right side, PBV may be underestimated. If the dispersion due to the volume of the right ventricle exceeds the dispersion due to the left chambers and that resulting from the distribution of pulmonary transit times, the underestimation of PBV is expected to be about one-half of the difference between the volume of the right ventricle and the volumes of the left-heart chambers (Fig-

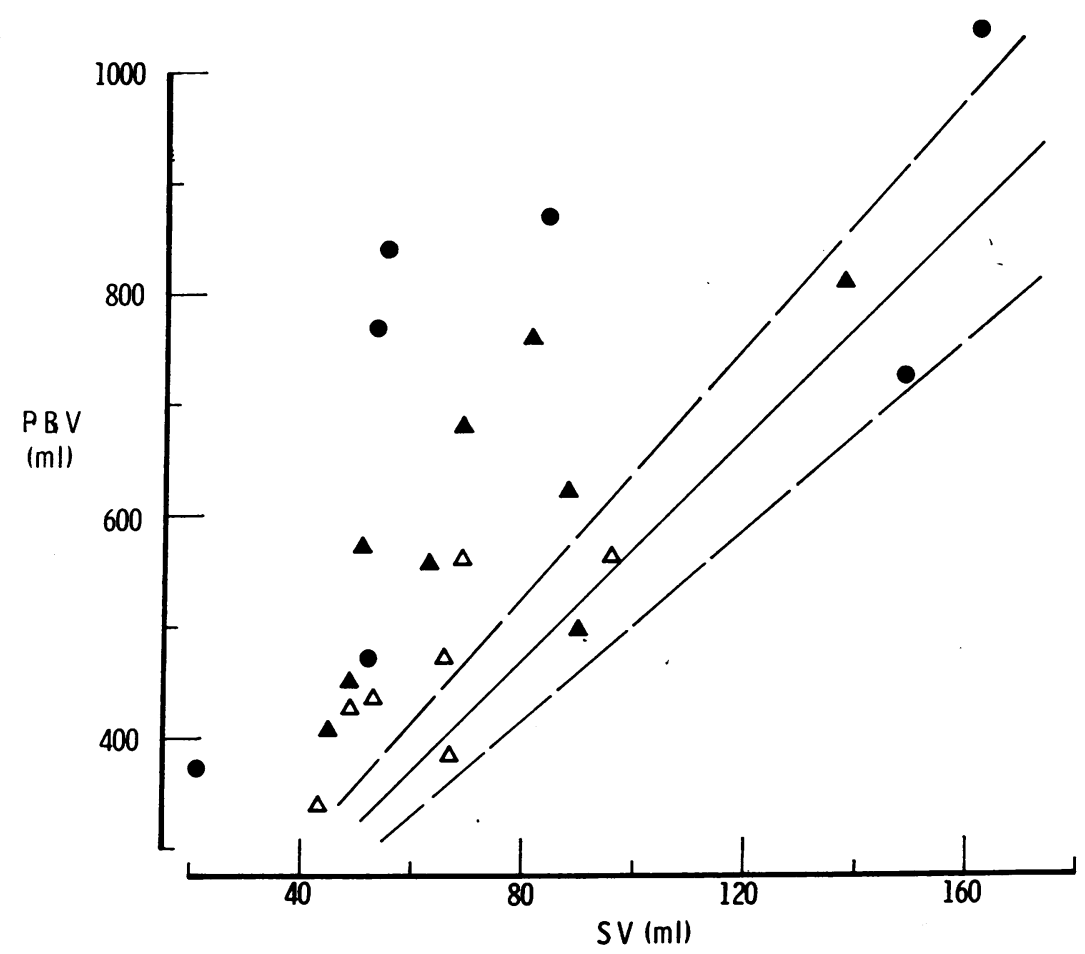

Fig. 6. Values of pulmonary blood volume obtained in 23 patients with CHRONIC BRONCHITIS AND EMPHYSEMA (OPEN TRIANGLES), COR PULMONALE (SOLID TRIANGLES), AND VARIOUS OTHER FORMS OF HEART DISEASE (CIRCLES) PLOTTED AGAINST THE STROKE VOLUME $(P B V=356+3 S V)$. The solid line represents the regression line of $P B V$ on stroke volume in 17 normal subjects, and the dashed lines represent $1 \mathrm{SD}$ from the regression line. 
TABLE IX

Reproducibility of the determination of pulmonary blood volume at rest

\begin{tabular}{|c|c|c|c|c|c|c|}
\hline Subject no. & $\mathrm{co}$ & $\mathrm{HR}$ & SV & PMTT & PBV & PBV \\
\hline 1,182 & $\begin{array}{c}L / \min / \mathrm{m}^{2} \\
5.68 \\
5.30\end{array}$ & $\begin{array}{c}\text { beats } / \text { min } \\
68 \\
66\end{array}$ & $\begin{array}{c}m l \\
84 \\
80\end{array}$ & $\begin{array}{c}\text { heart cycles } \\
9.1 \\
9.7\end{array}$ & $\begin{array}{l}m l \\
764 \\
774\end{array}$ & $\begin{array}{c}m l / m^{2} \\
402 \\
407\end{array}$ \\
\hline 1,250 & $\begin{array}{l}3.97 \\
4.00\end{array}$ & $\begin{array}{l}93 \\
94\end{array}$ & $\begin{array}{l}77 \\
77\end{array}$ & $\begin{array}{l}6.7 \\
6.9\end{array}$ & $\begin{array}{l}512 \\
530\end{array}$ & $\begin{array}{l}284 \\
294\end{array}$ \\
\hline 1,259 & $\begin{array}{l}2.72 \\
2.61\end{array}$ & $\begin{array}{l}64 \\
63\end{array}$ & $\begin{array}{l}68 \\
66\end{array}$ & $\begin{array}{l}5.8 \\
6.0\end{array}$ & $\begin{array}{l}392 \\
396\end{array}$ & $\begin{array}{l}245 \\
248\end{array}$ \\
\hline 1,261 & $\begin{array}{l}3.47 \\
3.68\end{array}$ & $\begin{array}{l}73 \\
74\end{array}$ & $\begin{array}{l}85 \\
89\end{array}$ & $\begin{array}{l}5.7 \\
5.4\end{array}$ & $\begin{array}{l}486 \\
482\end{array}$ & $\begin{array}{l}263 \\
261\end{array}$ \\
\hline 1,262 & $\begin{array}{l}3.61 \\
4.17\end{array}$ & $\begin{array}{l}43 \\
48\end{array}$ & $\begin{array}{l}162 \\
165\end{array}$ & $\begin{array}{l}6.4 \\
6.0\end{array}$ & $\begin{array}{r}1,037 \\
990\end{array}$ & $\begin{array}{l}540 \\
516\end{array}$ \\
\hline 1,263 & $\begin{array}{l}2.52 \\
2.48\end{array}$ & $\begin{array}{l}90 \\
85\end{array}$ & $\begin{array}{l}52 \\
54\end{array}$ & $\begin{array}{l}9.1 \\
7.5\end{array}$ & $\begin{array}{l}471 \\
406\end{array}$ & $\begin{array}{l}255 \\
219\end{array}$ \\
\hline 1,285 & $\begin{array}{l}3.89 \\
4.38\end{array}$ & $\begin{array}{l}92 \\
92\end{array}$ & $\begin{array}{l}69 \\
77\end{array}$ & $\begin{array}{l}8.1 \\
8.0\end{array}$ & $\begin{array}{l}560 \\
614\end{array}$ & $\begin{array}{l}344 \\
377\end{array}$ \\
\hline 1,289 & $\begin{array}{l}3.41 \\
3.76\end{array}$ & $\begin{array}{l}69 \\
69\end{array}$ & $\begin{array}{r}96 \\
105\end{array}$ & $\begin{array}{l}5.8 \\
6.2\end{array}$ & $\begin{array}{l}561 \\
648\end{array}$ & $\begin{array}{l}289 \\
334\end{array}$ \\
\hline 1,298 & $\begin{array}{l}2.82 \\
2.93\end{array}$ & $\begin{array}{l}102 \\
104\end{array}$ & $\begin{array}{l}43 \\
43\end{array}$ & $\begin{array}{l}8.0 \\
8.4\end{array}$ & $\begin{array}{l}340 \\
363\end{array}$ & $\begin{array}{l}221 \\
236\end{array}$ \\
\hline 1,338 & $\begin{array}{l}3.11 \\
3.44\end{array}$ & $\begin{array}{l}97 \\
95\end{array}$ & $\begin{array}{l}55 \\
62\end{array}$ & $\begin{array}{l}15.3 \\
14.4\end{array}$ & $\begin{array}{l}840 \\
893\end{array}$ & $\begin{array}{l}+91 \\
522\end{array}$ \\
\hline 1,351 & $\begin{array}{l}3.02 \\
2.67\end{array}$ & $\begin{array}{l}83 \\
85\end{array}$ & $\begin{array}{l}63 \\
54\end{array}$ & $\begin{array}{l}8.8 \\
9.8\end{array}$ & $\begin{array}{l}554 \\
531\end{array}$ & $\begin{array}{l}320 \\
307\end{array}$ \\
\hline 1,352 & $\begin{array}{l}4.27 \\
4.34\end{array}$ & $\begin{array}{l}63 \\
64\end{array}$ & $\begin{array}{l}138 \\
138\end{array}$ & $\begin{array}{l}5.9 \\
5.6\end{array}$ & $\begin{array}{l}807 \\
778\end{array}$ & $\begin{array}{l}398 \\
383\end{array}$ \\
\hline 1,367 & $\begin{array}{l}3.20 \\
2.98\end{array}$ & $\begin{array}{l}85 \\
86\end{array}$ & $\begin{array}{l}69 \\
63\end{array}$ & $\begin{array}{r}9.8 \\
11.3\end{array}$ & $\begin{array}{l}679 \\
709\end{array}$ & $\begin{array}{l}373 \\
390\end{array}$ \\
\hline
\end{tabular}

ure 4 , open circles). In the group of patients with cor pulmonale presented in Table IV, this underestimation is not expected to reach two stroke volumes in any instance.

Arrhythmias and valvular regurgitation may be expected to influence the determination of the pulmonary blood volume. Whereas an arrhythmia can make it difficult to determine the slope of the right curve and can disturb the steady state of the circulation, it does not seem to affect the reproducibility of the $\mathrm{PBV}$ in the two patients with atrial fibrillation (no. 1182 and 1262) and in the one with atrial flutter (no. 1263) of the present series (Table IX). When tricuspid regurgitation is such that the downslope of the right curve cannot be fitted with a single exponential, it is practically impossible to obtain, by precordial counting, a reliable measure of the mean ejection time of the right ventricle into the pulmonary artery. Since regurgitation through the mitral valve would be expected to delay the peak of the left curve more than predicted on the basis of the ratio of forward flow to the volumes of the left heart chambers, such patients were not studied.

Comparisons with previous determinations. The values for $\mathrm{PBV}$ obtained in normal persons agree with those published by Dock and associates (3). The agreement suggests that the different assumptions on which each technique rests do not involve any systematic error in patients with normal cardiopulmonary hemodynamics. The contribution of the left atrium to PBV is ill-defined with both of these techniques.

Donato and associates (11) have proposed an approximate method to derive $\mathrm{PBV}$ from radiocardiograms. It is difficult to define the limits of the volume measured by the method proposed by Donato and associates (11), but the same range of values was found in normal subjects as in the present series (20).

The value of $28 \%$ for the ratio of $\mathrm{PBV}$ to the total blood volume reported by Lammerant (6) is exceedingly high in comparison with the value of $10 \%$ found in this study. Moir and Gott (29), 
applying a method identical in principle to that of Lammerant, obtained an average value of $610 \mathrm{ml}$ per $\mathrm{m}^{2}$ for PBV. These high values are probably related to the inclusion in the mean transit time of the left curve of the circulation time through the left chambers together with the circulation times of all vascular sections between the left chambers and the point of injection.

Love, O'Meallie, and Burch (9) found that they could measure the "pulmonary blood volume" in a model of the central circulation if they subtracted the volume of one-half of the heart from the volume calculated according to Lammerant. Applying similar considerations to the data presented here, namely by subtracting twice the circulation time of the right curve from that of the left curve, we obtained values for $P B V$ that are in the same range as those presented in Table II, but with a wider scatter about the mean. There is no readily apparent explanation for the higher values (average, $490 \mathrm{ml}$ per $\mathrm{m}^{2}$ ) reported by Love and coworkers. In pathologic conditions, in which the two sides of the heart may differ significantly in size, the method above of deriving PMTT introduces into the calculation of $\mathrm{PBV}$ an error equal to the difference between the volumes of the $\mathrm{RH}$ and LH chambers.

Hakkila and Pietilä (8) and Eich, Chaffee, and Chodos (10) found values for the peak-to-peak time similar to those reported by Shipley, Clark, Liebowitz, and Krohmer (30), which are approximately $30 \%$ higher than the PMTT of $4.6 \mathrm{sec}-$ onds found in the present series. As Eich and associates point out, the volume measured on the basis of the peak-to-peak time includes blood contained in both sides of the heart. If the indicator is injected close to the heart, the difference between the peak-to-peak time and $t_{p}-T_{R V}$ corresponds to the turnover time of the right ventricle, which is 1.4 seconds on the average in the normal subjects of the present series.

Lagerlöf. Werkö, Bucht, and Holmgren attempted to calculate the PBV by subtracting the volume of blood in the left heart and the proximal arterial segments from the central blood volume measured by injecting dye into the pulmonary artery and sampling from the brachial artery (31). The volumes of the left heart and of the arterial tree were independently estimated on the basis of radiographic measurements of the total volume of the heart and of the cross-sectional area of the aorta. In seven normal subjects, they found a mean value of $19.5 \%$ for the ratio of $\mathrm{PBV}$ to total blood volume. This figure is twice the mean value given in Table II. The main reason for the discrepancy probably lies in the estimated volumes of blood in the left heart and arterial tree, which were indirectly evaluated. Furthermore, the extrapolation on semilogarithmic paper of a peripherally drawn curve represents a potential source of error, since the apparently linear downslope may not in fact be a simple exponential. Parrish and associates (21) have found in dogs a significant difference between PMTT calculated by applying the Hamilton method to curves drawn from the pulmonary veins, and the PMTT obtained using a sequential analysis that avoids extrapolation of the curves. It is relevant to observe here that an error in the extrapolation of a curve affects calculations of mean transit time more than those of cardiac output.

The values of PBV observed in patients with cardiopulmonary disease in this series cannot be compared with those obtained by Fujimoto, Kunieda, and Shiba (1), Milnor, Jose, and McGaff (2), and Dock and co-workers (3) because these authors studied patients with a different type of pathologic lesion. The values of 221 to $540 \mathrm{ml}$ found in this series for PBV:BSA, however, are in the same range reported by the authors above.

In patients with emphysema or cor pulmonale or both, the ratio of PBV to total blood volume is in the normal range, implying a normal distribution of blood between the systemic and pulmonary circulations, whereas in patients with heart disease other than cor pulmonale, this ratio may be elevated. In patients with cardiopulmonary disease of this series, the ratio of PBV to total blood volume, which ranged between $7 \%$ and $16 \%$, is considerably lower than the mean of $28 \%$ reported by Lammerant in normal subjects (6), and lower than the range of $11.3 \%$ to $40.1 \%$ reported by Lagerlöf, Werkö, Bucht, and Holmgren (31) for their patients with hypertensive cardiovascular disease or pulmonary disease.

Relationship of pulmonary blood volume to stroke volume. Milnor and associates (2) observed, in a group of 19 cardiac patients, most of whom had valvular lesions, that the correlation between PBV and stroke volume was closer than 
that between PBV and cardiac output. In the present study, this fact was observed in normal subjects as well as in patients with cardiopulmonary disease. In pathologic conditions, however, $\mathrm{PBV}$ is usually larger than that expected on the basis of the regression of PBV on stroke volume computed in normal subjects (Figure 6).

A strict correlation between PBV and stroke volume was demonstrated even in changing states. During mild leg exercise, or upon infusion of sodium bicarbonate or Tris solutions, changes in PBV were observed to parallel changes in stroke volume. A rise in cardiac output not accompanied by a comparable increase in stroke volume, as in the exercise study, was not associated with a significant increase in PBV. On the other hand, a rise in cardiac output associated with a similar change in stroke volume, as with infusion of sodium bicarbonate or Tris, was associated with a proportional increase in PBV. Under the conditions examined and for the variations of stroke volume that have been induced, the constancy of the pulmonary mean transit time, measured in heart cycles, suggests that the pulmonary vascular bed is distensible. It may be postulated that modifications of pulmonary vascular distensibility and of transmural pressure are responsible for the different relationship of PBV and stroke volume observed in patients with cardiopulmonary disease.

The concept advanced by some authors $(2,32)$, that the pulmonary or central blood volume exerts an important influence on the cardiac output, is not borne out by the exercise studies, which show that the cardiac output may rise considerably without significant increase in PBV.

\section{SUMMARY}

A method for obtaining pulmonary blood volume (PBV) from a double-peaked radiocardiogram is presented. The pulmonary mean transit time is estimated as the interval from the mean time of ejection of label from the right ventricle to the peak time of counting rate resulting from label in the left heart chambers.

The validity of the determination of the pulmonary mean transit time was analyzed with the aid of an electronic digital computer on a theoretical model of the central circulation, under varying conditions of flow, volume of the mixing cham- bers, counting efficiency of the detector, and distribution selected to represent the frequency function of the pulmonary transit times.

Analysis of the mathematical model has shown the degree to which the pulmonary mean transit time, as determined, is affected by variations in the volume of the heart chambers, in the counting efficiency, and in the distribution of the pulmonary transit times.

The mean PBV in 17 patients without cardiovascular disease was found to be $293 \mathrm{ml}$ per $\mathrm{m}^{2}$ body surface area. This value represents $10 \%$ of the total blood volume. A significant correlation was found between PBV and stroke volume, and to a lesser degree with cardiac output.

The ratio of PBV to total blood volume in patients with chronic bronchitis and emphysema, with or without cor pulmonale, was found to be the same as in the patients without heart disease. In patients with other forms of heart disease, however, this ratio may be elevated.

It has also been shown that PBV closely parallels the changes in stroke volume in changing states, such as during exercise, or the infusion of sodium bicarbonate or Tris. Variations in cardiac output, however, are not necessarily accompanied by changes in $\mathrm{PBV}$.

\section{ACKNOWLEDGMENTS}

The authors wish to acknowledge the helpful criticism of Drs. André Cournand, Domingo Gomez, and Luigi Donato.

\section{REFERENCES}

1. Fujimoto, K., R. Kunieda, and T. Shiba. Lung blood volume in acquired valvular disease. Jap. Heart J. 1960, 1, 442.

2. Milnor, W. R., A. D. Jose, and C. I. McGaff. Pulmonary vascular volume, resistance, and compliance in man. Circulation 1960, 22, 130.

3. Dock, D. S., W. L. Kraus, L. B. McGuire, J. W. Hyland, F. W. Haynes, and L. Dexter. The pulmonary blood volume in man. J. clin. Invest. 1961, 40, 317.

4. Schreiner, B. F., G. Glick, G. II. Murphy, and P. N. $\mathrm{Yu}$. The effects of exercise on the pulmonary blood volume in man. Fed. Proc. 1962, 21, 123.

5. Prinzmetal, M., E. Corday, H. C. Bergman, L. Schwartz, and R. J. Spritzler. Radiocardiography: a new method for studying the blood flow through the chambers of the heart in human beings. Science $1948,108,340$. 
6. Lammerant, J. Le Volume Sanguin des Poumons chez L'homme. Bruxelles, Arscia, 1957.

7. Gott, F. S., T. W. Moir, W. J. MacIntyre, and W. H. Pritchard. A mathematical model of dilution curves for flow study. Circulat. Res. 1961, 9, 607.

8. Hakkila, J., and K. A. Pietilä. Studies of cardiac output and pulmonary blood volume. Cardiologia (Basel) 1960, 37, 93.

9. Love, W. D., L. P. O'Meallie, and G. E. Burch. Clinical estimation of the volumes of blood in the right heart, left heart, and lungs by use of $\mathrm{I}^{131}$ albumin. Amer. Heart J. 1961, 61, 397.

10. Eich, R. H., W. R. Chaffee, and R. B. Chodos. Measurement of central blood volume by external monitoring. Circulat. Res. 1961, 9, 626.

11. Donato, L., C. Giuntini, M. L. Lewis, J. Durand, D. F. Rochester, R. M. Harvey, and A. Cournand. Quantitative radiocardiography. I. Theoretical considerations. Circulation 1962, 26, 174.

12. Stephenson, J. L. Theory of transport in linear biological systems: I. Fundamental integral equation. Bull. Math. Biophys. 1960, 22, 1.

13. Sherman, H. On the theory of indicator-dilution methods under varying blood-flow conditions. Bull. Math. Biophys. 1960, 22, 417.

14. Zierler, K. L. Theory of the use of arteriovenous concentration differences for measuring metabolism in steady and non-steady states. J. clin. Invest. 1961, 40, 2111.

15. Chiarugi, G. Instituzioni di Anatomia dell'Uomo. Milan, Società Edizioni Libraria, 1930, vol. 2.

16. Soloff, L. A., and J. Zatuchni. Cardiac chamber volumes and their significance in rheumatic heart disease with isolated mitral stenosis. Circulation 1959, 19, 269.

17. Folse, R., and E. Braunwald. Determination of fraction of left ventricular volume ejected per beat and of ventricular end-diastolic and residual volumes. Experimental and clinical observations with a precordial dilution technic. Circulation 1962, 25, 674.

18. Gleason, W. L., and E. Braunwald. Studies on Starling's law of the heart. VI. Relationships between left ventricular end-diastolic volume and stroke volume in man with observations on the mechanism of pulsus alternans. Circulation 1962, 25, 841.

19. Johnston, R. R., C. E. Rackley, H. J. Sauter, and H. T. Dodge. Functional characteristics of the left atrium in man. Clin. Res. 1962, 10, 174.

20. Lewis, M. L., C. Giuntini, L. Donato, R. M. Harvey, and A. Cournand. Quantitative radiocardiography.
III. Results and validation of theory and method. Circulation 1962, 26, 189.

21. Parrish, D., D. T. Hayden, W. Garrett, and R. L. Huff. Analog computer analysis of flow characteristics and volume of the pulmonary vascular bed. Circulat. Res. 1959, 7, 746.

22. Howard, A. R., W. F. Hamilton, and P. Dow. Limitations of the continuous infusion method for measuring cardiac output by dye dilution. Amer. J. Physiol. 1953, 175, 173.

23. Donato, L., D. F. Rochester, M. L. Lewis. J. Durand, J. O. Parker, and R. M. Harvey. Quantitative radiocardiography. II. Technique and analysis of curves. Circulation 1962, 26, 183.

24. Chaplin, H., P. L. Mollison, and H. Vetter. The body/venous hematocrit ratio: its constancy over a wide hematocrit range. J. clin. Invest. 1953, 32, 1309.

25. Giuntini, C., R. Bianchi, P. Toni, and L. Donato. Confronto fra la registrazione con integratore e quella con la scala dei tracciati radiocardiografici. Minerva nucl. 1961, 5, 218.

26. Fritts, H. W., Jr., P. Harris, C. A. Chidsey III, R. H. Clauss, and A. Cournand. Validation of a method for measuring the output of the right ventricle in man by inscription of dye-dilution curves from the pulmonary artery. J. appl. Physiol. 1957, 11,362 .

27. Rochester, D. F., J. Durand, J. O. Parker, H. W. Fritts, Jr., and R. M. Harvey. Estimation of right ventricular output in man using radioactive krypton $\left(\mathrm{Kr}^{85}\right)$. J. clin. Invest. 1961, 40, 643.

28. Hamlin, R. L., W. P. Marsland, C. R. Smith, and L. A. Sapirstein. Fractional distribution of right ventricular output in the lungs of dogs. Circulat. Res. 1962, 10, 763.

29. Moir, T. W., and F. S. Gott. The measurement of central circulating blood volume from precordial dilution curves in normal subjects and patients with mitral stenosis (abstract). J. Lab. clin. Med. 1959, 54, 926.

30 Shipley, R. A., R. E. Clark, D. Liebowitz, and J. S. Krohmer. Analysis of the radiocardiogram in heart failure. Circulat. Res. 1953, 1, 428.

31. Lagerlöf, H., L. Werkö, H. Bucht, and A. Holmgren. Separate determination of the blood volume of the right and left heart and the lungs in man with the aid of the dye injection method. Scand. J. clin. Lab. Invest. 1949, 1, 114.

32. Warren, J. V., and A. M. Weissler. Central blood volume as a factor in the regulation of the circulation (abstract). Circulation 1958, 18, 793. 